\title{
Methotrexate treatment for rheumatoid arthritis in Poland: Retrospective analysis of patients in routine clinical practice
}

\author{
Jerzy Świerkot ${ }^{1}$, Bogdan Batko ${ }^{2}$, Piotr Wiland ${ }^{1}$, Mariusz Jędrzejewski ${ }^{3}$, Marcin Stajszczyk ${ }^{4}$ \\ ${ }^{1}$ Department of Rheumatology and Internal Medicine, Wroclaw Medical University, Poland \\ 2Department of Rheumatology, J. Dietl Specialist Hospital, Krakow, Poland \\ ${ }^{3}$ GfK Polonia, Warsaw, Poland \\ ${ }^{4}$ Department of Rheumatology and Autoimmune Diseases, Silesian Rheumatology Centre, Ustron, Poland
}

\begin{abstract}
Objectives: The aim of this study was to evaluate methotrexate (MTX) treatment administered by Polish rheumatologists in everyday practice.

Material and methods: The study was based on a retrospective analysis of a cohort of $1957 \mathrm{pa}-$ tients with rheumatoid arthritis (RA). It was conducted among 100 rheumatologists, each of whom received 20 questionnaires and completed them based on the data from their rheumatoid arthritis patients.

Results: Methotrexate was taken by $91 \%$ of patients, and $80 \%$ of them continued the treatment either as a monotherapy (65\%) or concomitantly with other disease-modifying anti-rheumatic drugs. In $60 \%$ of the cases, therapy was initiated within six months of diagnosis. Dose modifications were observed in $76 \%$ of cases and were contingent on different factors, e.g. lack of efficacy, presence of adverse events. The most prevalent adverse events were nausea and vomiting, weakness, and elevated liver enzyme activity. The most common initial dose of MTX was 10 or $15 \mathrm{mg} /$ week. An increase in dose to the maximum of $25 \mathrm{mg} /$ week was observed in $36 \%$ of cases, with continuation for $27 \%$ of patients. Treatment interruption was noted in $21 \%$ of patients, predominantly due to MTX intolerance; however, in $13 \%$ of cases, it was due to patient choice.

Conclusions: Methotrexate is the most common agent used to treat rheumatoid arthritis. Dose modifications are often applied to maximise efficacy and reduce adverse reactions, which could lead to withdrawal. Methotrexate is an effective drug for treatment of RA when used according to current recommendations. To optimise MTX therapy, regular medical visits are required.
\end{abstract}

Key words: methotrexate, rheumatoid arthritis, everyday practice, treatment.

\section{Introduction}

The goal of rheumatoid arthritis (RA) therapy is to obtain remission or low disease activity. According to the guidelines of all major rheumatological associations (European League Against Rheumatism [EULAR], American College of Rheumatology [ACR]), treatment with a synthetic disease-modifying antirheumatic drug (sDMARD) should be initiated as soon as possible after disease diagnosis [1-3]. Rheumatoid arthritis treatment plans should be based on a mutual decision between patient and rheu- matologist. It is evident that more physicians acknowledge the necessity for a change in treatment therapy due to the shortened time frame between the diagnosis and disease-modifying antirheumatic drug (DMARD) administration from 120 months in 1965, to 30 months in 1975, five months in 1985, and zero to two months presently. For the past 20 years, the main sDMARD used in clinical practice has been methotrexate (MTX). Recommendations on the administration of MTX in everyday practice have been published in several articles [1, 4-6]. Methotrexate should be rapidly escalated, usually to 
25-30 mg/week, orally or subcutaneously administered, with folic acid supplementation, and the maximal MTX dose, if tolerated, should be sustained for about 8-12 weeks to judge the MTX treatment response $[1,7]$.

Remission or at least low disease activity should be obtained within six months, and at least $50 \%$ clinical improvement within three months is desirable. If therapeutic goals are not accomplished with the first line of treatment and there are poor prognostic factors, the possibility of adding a biological agent to treatment should be considered. The importance of MTX therapy in the treatment of RA is clear, despite the introduction of new biological agents for RA treatment. New biological agents should be used together with MTX if there are no contraindications $[1-3,5-8]$. Methotrexate is currently administered to over 500,000 rheumatoid arthritis patients worldwide. A good response to treatment is obtained in $35 \%$ to $65 \%$ of patients, and in $10 \%$ to $30 \%$ of patients treatment is discontinued due to adverse events.

Table I. Time of MTX initiation and duration of MTX therapy

\begin{tabular}{|c|c|}
\hline $\begin{array}{c}\text { Duration of MTX therapy (in months) } \\
(n=1781, \text { patients who had used MTX at any time) }\end{array}$ & Patients \\
\hline $0-2$ & $4.4 \%$ \\
\hline $3-6$ & $7.5 \%$ \\
\hline $7-12$ & $8 \%$ \\
\hline $13-24$ & $17.4 \%$ \\
\hline $25-60$ & $32 \%$ \\
\hline $61-96$ & $14 \%$ \\
\hline $97-180$ & $11.5 \%$ \\
\hline$>180$ & $2.7 \%$ \\
\hline No answer to the question & $2.5 \%$ \\
\hline Average in months & 51.3 \\
\hline Median in months (min.-max.) & $\begin{array}{c}35.6 \\
(<1-364)\end{array}$ \\
\hline \multicolumn{2}{|l|}{$\begin{array}{l}\text { Time elapsed from time of diagnosis to MTX } \\
\text { treatment initiation (in months) } \\
\text { ( } n=1781 \text {, patients who had used MTX at any time) }\end{array}$} \\
\hline 0 (at the time of diagnosis) & $45 \%$ \\
\hline $1-6$ & $15 \%$ \\
\hline $7-24$ & $10 \%$ \\
\hline $25-60$ & $11 \%$ \\
\hline $61-120$ & $8 \%$ \\
\hline$>120$ & $7 \%$ \\
\hline No answer to the question & $4 \%$ \\
\hline Average in months & 29.2 \\
\hline Median in months (min.-max.) & $\begin{array}{c}0.49 \\
(0-571)\end{array}$ \\
\hline
\end{tabular}

The aim of this study was to evaluate MTX treatment administered by Polish rheumatologists in everyday practice.

\section{Material and methods}

The study was conducted among 100 rheumatologists from different centres across Poland, which were chosen to reflect the current global structure of RA treatment in Poland. During sample selection a percentage distribution of rheumatologists in every region was used, which was calculated based on the data from the Polish Chamber of Physicians. Every physician obtained 20 questionnaires that were supposed to be filled out during the next 20 visits of patients with RA. The questionnaires were filled out after each visit based on medical records and patient history. Besides questions regarding general patient information, the diagnostic process, and administered treatment, the questionnaire also included detailed questions about MTX treatment. These questions pertained to the start date and end date of treatment, evaluation of disease activity, and doses of the administered drug including the maximal dose and the dose at the beginning of treatment. The questionnaire requested detailed information regarding any dose modifications and the reasons for them, adverse events, and reasons for discontinuing MTX administration. Ethical approval and informed consent (according to the Declaration of Helsinki) was obtained.

\section{Results \\ Sample characteristics}

A total of 100 rheumatologists participated in the study by completing questionnaires regarding their RA patients, and a total of 1957 questionnaires were collected. Among the patients treated with MTX, 79\% were women and the median age was 58.1 years.

\section{Methotrexate use}

Patients who had taken MTX at any time constituted $91 \%$ of all the examined patients (1781), and in $61 \%$ of them MTX was the first sDMARD used. At the time of filling out the questionnaires, $80 \%$ of all the patients were still taking MTX. Of those patients still taking MTX, $81 \%$ were taking it as monotherapy, $16.2 \%$ were taking it in combination therapy with another SDMARD, and $2.8 \%$ were taking it in combination therapy with a biological agent. The mean duration of MTX administration among the examined patients was 51.3 months (median 35.6 months). Patients who took MTX for less than three months constituted $4.4 \%$ of patients who had taken MTX at any time. The largest group consisted of patients 
taking MTX from two to five years (32\%) (Table I). The last dose of MTX was administered orally in $82 \%$ of patients and subcutaneously in $18 \%$ of patients who had taken MTX at any time.

Methotrexate was used as a first-line therapy in $75 \%$ of patients with the disease for up to one year. The median duration from the time of diagnosis to initiation of MTX therapy was not even half a month (0.49 month) for all patients who had taken MTX at any time (Table I).

\section{Treatment interruption}

Methotrexate treatment was interrupted in $21 \%$ of all patients who had taken MTX at any time. The most common reasons were gastrointestinal adverse events, treatment contraindications, or patient choice (Table II). Depending on the length of MTX therapy, other reasons for treatment discontinuation were observed. For example, for patients who had taken MTX for one to two years or 10 to 15 years, infection was the reason for treatment discontinuation in $17 \%$ and $20 \%$ of patients, respectively. The risk of permanent discontinuation of MTX treatment increased together with duration of treatment (in patients who used MTX for up to six months, it was present in less than $10 \%$; in patients treated for over five years, it was present in 20\%; and when treatment was administered for over eight years, it was present in one-third of the patients). Between the $7^{\text {th }}$ and $12^{\text {th }}$ month of MTX treatment, the main reason for discontinuation of treatment was drug intolerance (44\%) or a patient choice (34\%).

\section{Methotrexate dose}

During treatment, MTX dose was modified in $76 \%$ of patients; the dose was decreased in $24 \%$ of these cases, increased in $61 \%$, and both increased and decreased in $15 \%$. The main reasons for dose reduction were adverse events and remission, whereas the main reason for dose increase was ineffective treatment. The adverse events leading to MTX dose modification were nausea and vomiting, malaise and general weakness, increased activity of liver enzymes, and hair loss (Table III). The average starting dose for MTX therapy was $13.4 \mathrm{mg} /$ week (median $11.9 \mathrm{mg}$ / week), whereas most commonly, treatment was started with $10 \mathrm{mg} /$ week (in 36\% of patients) or $15 \mathrm{mg} /$ week (in $32 \%$ of patients). The average maximal dose obtained during treatment was 20.2 mg/week (median $19.3 \mathrm{mg}$ / week). The most common dosages among patients that were currently taking MTX were $25 \mathrm{mg} /$ week (27\%), $20 \mathrm{mg} /$ week (24\%), and $15 \mathrm{mg} /$ week (21\%) (Table IV).

Subcutaneous MTX was used in $18 \%$ of patients. The last administered dose in these patients was usually $25 \mathrm{mg} /$ week (46\%), and the lowest dose of $15 \mathrm{mg} /$ week was administered in only $6 \%$ of patients.
Table II. Reported reasons for MTX treatment discontinuation

\begin{tabular}{|lc|}
\hline $\begin{array}{l}\text { Reasons for MTX discontinuation }(n=374, \\
\text { patients in whom MTX use was discontinued })\end{array}$ & $\begin{array}{c}\text { Patients } \\
(\%)\end{array}$ \\
\hline Gastrointestinal side effects & 29 \\
\hline Contraindications to MTX use & 13 \\
\hline Patient choice & 13 \\
\hline Remission & 10 \\
\hline Perioperative period & 7 \\
\hline Infections & 6.4 \\
\hline Leukopaenia/anaemia & 5 \\
\hline Planned pregnancy & 4 \\
\hline Elevated levels of aminotransferases & 3 \\
\hline Ineffective treatment & 2.6 \\
\hline Other & 4 \\
\hline No answer to the question & 3 \\
\hline
\end{tabular}

Table III. Reported side effects resulting in MTX dose modification or discontinuation. The sum is larger than $100 \%$ because some patients had more than one side effect

\begin{tabular}{|lc|}
\hline $\begin{array}{l}\text { Types of side effects } \\
(n=303)\end{array}$ & $\begin{array}{c}\text { Patients } \\
\text { (\%) }\end{array}$ \\
\hline Nausea/vomiting & 49.6 \\
\hline General weakness/malaise & 41.2 \\
\hline Elevated levels of aminotransferases & 31.5 \\
\hline Hair loss & 18.1 \\
\hline Anaemia/leukopaenia & 3.3 \\
\hline Deterioration of renal function & 2.9 \\
\hline Abdominal/stomach pain & 2.9 \\
\hline Skin changes & 1.6 \\
\hline Others & 8.5 \\
\hline
\end{tabular}

\section{Disease activity}

At the time of MTX therapy initiation, patients were characterised with moderate or high disease activity. Most patients who were still using MTX at the time of the study had a lower number of painful and swollen joints in comparison to the beginning of their treatment. A similar situation is observed in regard to ESR and CRP, but more than a half of the patients still had elevated inflammatory markers.

\section{Effectiveness of treatment}

According to EULAR guidelines, the RA treatment goal should be to obtain remission or to reduce disease 
Table IV. Methotrexate dosing

\begin{tabular}{|c|c|c|c|}
\hline $\begin{array}{c}\text { Doses of MTX } \\
(n=1781, \text { patients }\end{array}$ & Starting treatment dose & $\begin{array}{l}\text { Maximal dose obtained during } \\
\text { treatment }\end{array}$ & Last administered dose \\
\hline $\begin{array}{l}\text { who had taken MTX } \\
\text { at any time) }\end{array}$ & Patients (\%) & Patients (\%) & Patients (\%) \\
\hline$\leq 7.5 \mathrm{mg} /$ week & 8 & 2 & 3 \\
\hline $10 \mathrm{mg} /$ week & 36 & 8 & 13 \\
\hline $12.5 \mathrm{mg} /$ week & 8 & 6 & 7 \\
\hline $15 \mathrm{mg} /$ week & 31 & 14 & 21 \\
\hline 17.5 & 1 & 1.5 & 2 \\
\hline 20 & 11 & 26 & 24 \\
\hline 22.5 & 0 & 1.3 & 0.7 \\
\hline 25 & 2 & 36 & 27 \\
\hline 27.5 & 0 & 0.4 & 0.3 \\
\hline 30 & 0 & 4 & 1 \\
\hline No answer & 3 & 0.8 & 1 \\
\hline Average dose & 13.4 mg/week & 20.2 mg/week & 18.2 mg/week \\
\hline Median & 11.9 mg/week & 19.3 mg/week & 17.9 mg/week \\
\hline
\end{tabular}

Table V. Parameters evaluating disease activity before and after 3-6 months of MTX treatment

\begin{tabular}{|c|c|c|}
\hline \multirow[t]{3}{*}{ Measured parameter } & \multicolumn{2}{|c|}{$\begin{array}{l}\text { Patients taking MTX for } \\
3-6 \text { months }\end{array}$} \\
\hline & $\begin{array}{l}\text { At the } \\
\text { beginning } \\
\text { of therapy } \\
(n=101)\end{array}$ & $\begin{array}{c}\text { After 3-6 } \\
\text { months } \\
(n=101)\end{array}$ \\
\hline & Patients (\%) & Patients (\%) \\
\hline Number of swollen joints $\geq 3$ & 88 & 40 \\
\hline Number of swollen joints $\leq 1$ & 21 & 57 \\
\hline Number of painful joints $\geq 3$ & 99 & 52 \\
\hline Number of painful joints $\leq 1$ & 0.3 & 48 \\
\hline $\mathrm{ESR}>15 \mathrm{~mm} / \mathrm{h}$ & 84 & 58 \\
\hline \multicolumn{3}{|l|}{ DAS-28: } \\
\hline$\leq 2.6$ & 0 & 45 \\
\hline $2.61-3.2$ & 0 & 17 \\
\hline $3.21-5.1$ & 41 & 26 \\
\hline$>5.1$ & 59 & 12 \\
\hline
\end{tabular}

activity after three to six months. Therefore, to evaluate the effectiveness of RA treatment in Poland, a group of patients (101) who were treated from three to six months were selected. In more than a half of the patients (62\%) remission or reduction of disease activity were diagnosed based on DAS-28. Patients with a moderate and high disease activity constituted $41 \%$ and
$59 \%$, respectively, at the moment of therapy initiation and $26 \%$ and $12 \%$, respectively, after three to six months of MTX treatment (Table V).

\section{Discussion}

The results of this study show that over $90 \%$ of the observed RA patients have used MTX in the past. Methotrexate was the initial treatment as a monotherapy chosen by most rheumatologists, which is in accordance with the EULAR and ACR guidelines [1, 3]. The results of earlier research studies indicate that in selected groups of patients with a very active course of disease and risk factors indicating a fast progression of disease, it may be appropriate to administer more than one sDMARD in combination therapy as a first-line treatment [9].

It is important to start treatment with a SDMARD as soon as possible after RA diagnosis because this provides the highest probability to achieve remission [10]. In $60 \%$ of patients, MTX was administered in the first six months after the diagnosis of RA (in $45 \%$ immediately after the diagnosis), and the median duration from the moment of diagnosis to administration of MTX was approximately half a month. It would be interesting to evaluate the reasons why MTX was not administered immediately after diagnosis. We must acknowledge that some patients have contraindications to the use of MTX, and some patients do not accept or consent to MTX therapy due to fear and the risk of toxic adverse events. Continued education of the necessity for imme- 
diate administration of sDMARD medications is crucia for rheumatologists, primary care doctors, and patients. Unfortunately, only $15 \%$ of patients with RA consult with a rheumatologist in the first 12 weeks of disease [11].

Presently, there is much optimism associated with the individualisation of treatment in patients with RA For half of the surveyed patients, MTX was used as a first-line therapy. These were the patients with a variable duration of disease. The fact that Polish rheumatologists closely follow the rheumatological guidelines and have significant knowledge on this topic is confirmed by the obtained data, showing that in patients with RA duration of up to one year, $75 \%$ of them were given MTX as the main method of treatment. Current data on optimal methotrexate therapy are more optimistic than those analysed in previous years [12]

Similarly, Scandinavian rheumatologists treat earlyonset RA with MTX in $77 \%$ of patients, sulfasalazine in $19 \%$, leflunomide in $2 \%$, and combination therapy in $2 \%$ [13]. Anderson et al. [14] conducted a meta-analysis of 14 clinical studies (1435 patients), which indicated that the most important factor influencing MTX treatment response is the duration of the disease; in patients with a long RA duration MTX was less effective. If MTX was administered during the first year of the disease the success rate was 53\%, and when RA lasted longer than 10 years the effectiveness dropped to $35 \%[14,15]$.

The results of an analysis based on 101 patients in whom treatment was administered for three to six months show that the treatment decisions made by Polish rheumatologists are reasonable and in accordance with well-defined guidelines. In response to active MTX treatment, more than half of the patients (62\%) obtained remission or reduction of disease activity, which was evaluated based on DAS28. We realise that it is not possible to reach therapeutic goals in all the patients. Two-fifths of the patients did not achieve the desired therapeutic goal. This indicates the need for constant therapy modification and better physician-patient cooperation.

It is important to identify and understand factors leading to MTX treatment interruption. The most common (60\%) reasons reported for treatment interruption in this study included adverse events, contraindications to MTX therapy, and planning a pregnancy. In the current study, the most common adverse events of MTX treatment were gastroenterological symptoms, nausea, dyspeptic symptoms, and abdominal pain. The profile and frequency of adverse events reported in the study questionnaire are in accordance with those described in the literature [16-19]. While these common adverse events can be associated with the administration of MTX, it is always important to take a thorough patient history to verify if they are not caused by other reasons such as administration of NSAIDs, dietary changes, or stress. If the observed adverse events are associated with oral MTX therapy, then subcutaneous MTX therapy should be attempted. It is also important to recognise the rare, but more dangerous complications of MTX treatment such as significant increase of aminotransferases, infections, and leukopaenia. In the observed group, infections were diagnosed more commonly at the beginning of treatment or in patients with long-standing RA. These adverse events may be associated with a frequent onetime administration of glucocorticosteroids, and an older age in patients with long-standing RA. In most cases, there is no need for MTX dose modification when upper respiratory infections occur. But in cases of pneumonia, most authors recommend a temporary discontinuation of MTX [20]. Pneumavax vaccination should be administered in all RA patients, especially in older men with a history of lung disease [21].

Two of the most commonly reported adverse events were general weakness and malaise. The feeling of tiredness and general weakness can be caused by a discontinuation of MTX in up to $20 \%$ of patients who have stopped therapy [17]. Sometimes it is enough to divide the dose into two or three parts and administer it every 12 hours, to lower the MTX dose, or to administer MTX on a day off from work. Interestingly, drug intolerance was reported as the reason for treatment discontinuation in $31 \%$ of the women but in only $18 \%$ of the men. However, significantly more men discontinued treatment without previous agreement from the doctor than women ( $27 \%$ and $10 \%$, respectively).

In current practice, significant emphasis is placed on the treatment decision-making process by the physician and patient together. Physicians should ensure that patients understand that MTX treatment has been shown to be associated with a $70 \%$ decrease in mortality among patients with RA and a lower mortality due to cardiovascular causes [22, 23]. After obtaining a remission, when glucocorticoids are no longer administered, a gradual lowering of the MTX dose can be considered, elongating the period between administered doses. However, MTX should not be discontinued abruptly.

Particular attention should be paid to patients between the $6^{\text {th }}$ and $12^{\text {th }}$ month of treatment. During that time, most patients discontinued MTX treatment because of drug intolerance (44\%) or without previous agreement from their physician (34\%). A problem that occurs after reaching the therapeutic goal is that it often discourages patients from continuing MTX treatment. In these cases, the physician's role in therapy modification is crucial to prevent abrupt treatment discontinuation by the patient. Additionally, based on previous observa- 
tions, there is no need for MTX discontinuation during the perioperative period. In the observed group, treatment was discontinued in $7 \%$ of cases.

Based on the data from the study survey, we observed favourable trends regarding the administration of appropriate MTX doses in patients with RA. Seventy-five per cent of rheumatologists recommended a starting dose between $10 \mathrm{mg}$ and $15 \mathrm{mg}$ once a week, which is the suggested dosing of most recommendations [1-3]. On average, it is recommended that the MTX dose be rapidly increased, usually to $25-30 \mathrm{mg} /$ week, if therapeutic goals are not achieved and if there are no adverse events associated with MTX [1]. Approximately three-fourths of patients evaluated at their last visit had been given an MTX dose between $15 \mathrm{mg}$ and $30 \mathrm{mg}$. It should be emphasised that by taking a chronic MTX dose of $30 \mathrm{mg}$ every week, the monthly dose is $120 \mathrm{mg}$, and the yearly dose is $1440 \mathrm{mg}$. This is why laboratory tests (CBC, AST, ALT) must be routinely administered during therapy to identify possible adverse events. The correlation between the degree of liver fibrosis and the cumulative MTX dose together with the possibility of assessing the advancement of these changes in elastography are still debatable $[24,25]$. The sensitivity of elastography in the early stages of fibrosis is $56 \%$ to $67 \%$ and specificity is $89 \%$ to $91 \%$.

The approach of French rheumatologists seems to be appropriate; they observed the need to adjust MTX dose according to patient weight [2]. According to them, the appropriate MTX dose is $0.3 \mathrm{mg} / \mathrm{kg} /$ week. These recommendations, however, were not included in the latest EULAR recommendations [1]. In order to individualise patient therapy for best results, we should consider whether to administer a maximal dose of MTX, change the route of administration to subcutaneous, or add other sDMARD or biological agents.

Subcutaneous MTX was administered in almost one-fifth of the patients, indicating awareness among the survey physicians of this therapy option. The last administered doses of subcutaneous MTX were usually high (in $46 \%$ of patients it was $25 \mathrm{mg} /$ week) which could indicate that the reason for changing the route of administration was due to ineffectiveness. The average dose was also higher for subcutaneous MTX than for oral (21 mg and $17 \mathrm{mg} /$ week, respectively). Changing to subcutaneous administration should be considered when oral treatment is ineffective, when there is a failure to comply with recommendations, when there are gastrointestinal adverse events, or before the biological treatment [5, 26-29]. It should be emphasised that patients positively evaluated the possibility of self-administered injections of subcutaneous MTX.
Besides the administered dose, it is important to constantly adjust therapy to current disease activity and potential adverse events. Considering the data from the survey, it seems that most Polish physicians are aware of this. The MTX dose was modified in more than threefourths of patients. The necessity for frequent follow-up visits should be emphasised, especially in the beginning of therapy.

When administered in accordance with current recommendations MTX is a safe drug, and its use is appropriate considering its effectiveness and adverse events $[1,3,6]$. Some studies have confirmed MTX therapy duration of over five years in $74 \%$ of patients, and at least 12 years in more than $50 \%$ of patients [30]. It is pleasing to see that more physicians and patients see the advantages of MTX use. The demonstrated advantages of MTX include:

- a higher percentage of patients continue long-term therapy with MTX when compared to other SDMARDs,

- MTX has a relatively short time from initiation of therapy to onset of therapeutic effects,

- MTX has a relatively low cost,

- MTX can be used in both monotherapy and combination therapy,

- increases the effectiveness of biological drugs,

- MTX has the best ratio of effectiveness/toxicity among all sDMARDs [4, 6, 7, 19].

\section{Conclusions}

1. Methotrexate is an effective drug for treatment of RA when used according to current recommendations.

2. Dose modifications of MTX are often applied to maximise efficacy and reduce adverse reactions, which could lead to withdrawal.

3. To optimise MTX therapy, regular medical visits are required.

The authors declare no conflict of interest. This study received financial support from Roche.

\section{References}

1. Smolen JS, Landewé R, Bijlsma J, et al. EULAR recommendations for the management of rheumatoid arthritis with synthetic and biological disease-modifying antirheumatic drugs: 2016 update. Ann Rheum Dis 2017; 76: 960-977.

2. Gaujoux-Vialaa C, Gossecb L, Cantagrelc A, et al. Recommendations of the French Society for Rheumatology for managing rheumatoid arthritis. Joint Bone Spine 2014; 81: 287-297.

3. Singh JA, Saag KG, Bridges SL Jr, et al. 2015 American College of Rheumatology Guideline for the Treatment of Rheumatoid Arthritis. Arthritis Rheum 2016; 61: 1-26. 
4. Visser K, Katchamart W, Loza E, et al. Multinational evidence-based recommendations for the use of methotrexate in rheumatic disorders with a focus on rheumatoid arthritis: integrating systematic literature research and expert opinion of a broad international panel of rheumatologists in the $3 \mathrm{E}$ Initiative. Ann Rheum Dis 2009; 68: 1086-1093.

5. Molina J. Recommendations for the Use of MTX in RA. Reumatol Clin 2015; 11: 3-8.

6. Bello AE, Perkins EL, Jay R, Efthimiou P. Recommendations for optimizing methotrexate treatment for patients with rheumatoid arthritis. Open Access Rheumatol 2017; 9: 67-79.

7. Kłak A, Paradowska-Gorycka A, Kwiatkowska B, Raciborski F. Personalized medicine in rheumatology. Reumatologia 2016 54: 177-186.

8. Burmester GR, Pope JE. Novel treatment strategies in rheumatoid arthritis. Lancet 2017; 10: 2338-2348.

9. Graudal N, Hubeck-Graudal T, Tarp S, et al. Effect of Combination Therapy on Joint Destruction in Rheumatoid Arthritis: A Network Meta-Analysis of Randomized Controlled Trials. PLOS One 2014; 9: e106408.

10. Bakker MF, Jacobs JW, Welsing PM, et al. Early clinical response to treatment predicts 5-year outcome in RA patients: follow-up results from the CAMERA study. Ann Rheum Dis 2011 70: 1099-1113.

11. NICE commissioning guides. Support for commissioning for rheumatoid arthritis [CMG51] 01 June 2013 http://www.nice. org.uk/guidance/cmg51.

12. Kulig M, Malec Z, Tłustochowicz W. Analiza leczenia ambulatoryjnego metotreksatem chorych na reumatoidalne zapalenie stawów. Reumatologia 2009; 47: 202-206.

13. Nikolaisen C, Kvien TK, Mikkelsen K, et al. Contemporary use of disease-modifying drugs in the management of patients with early rheumatoid arthritis in Norway. Scand J Rheumatol 2009; 19: 1-6.

14. Anderson JJ, Wells G, Verhoeven AC, Felson DT. Factors predicting response to treatment in rheumatoid arthritis: the importance of disease duration. Arthritis Rheum 2000; 43: 22-29.

15. Saevarsdottir S, Wallin $H$, Seddighzadeh $M$, et al. Predictors of response to methotrexate in early DMARD naïve rheumatoid arthritis: results from the initial open-label phase of the SWEFOT trial. Ann Rheum Dis 2011; 70: 469-475.

16.Świerkot J, Sokolik R, Gruszecka-Marczynska K, et al. Skuteczność leczenia i występowanie działań niepożądanych w trakcie terapii metotreksatem podawanym doustnie i podskórnie chorym na reumatoidalne zapalenie stawów. Reumatologia 2008; 46: 322-329.

17. Nikiphorou E, Negoescu A, Fitzpatrick JD, et al. Indispensable or intolerable? Methotrexate in patients with rheumatoid and psoriatic arthritis: a retrospective review of discontinuation rates from a large UK cohort. Clin Rheumatol 2014; 33: 609614.

18. Curtis J, Bykerk V, Aassi M, Schiff M. Adherence and Persistence with Methotrexate in Rheumatoid Arthritis: A Systematic Review. J Rheumatol 2016; 43: 1997-2009.

19. Lopez-Olivo MA, Siddhanamatha HR, Shea B, et al. Methotrexate for treating rheumatoid arthritis. Cochrane Database Syst Rev 2014; 10: CD000957.
20. Bogas M. Methotrexate treatment in rheumatoid arthritis. Clin Rheumatol 2010; 29: 629-635.

21. Coulson E, Saravanan V, Hamilton J, et al. Pneumococcal antibody levels after pneumovax in patients with rheumatoid arthritis on methotrexate. Ann Rheum Dis 2011; 70: 1289-1291.

22. Micha R. Systematic Review and Meta-Analysis of Methotrexate Use and Risk of Cardiovascular Disease. Am J Cardiol 2011; 108: 1362-1370.

23. Wasko MC, Dasgupta A, Hubert $\mathrm{H}$, et al. Propensity-adjusted association of methotrexate with overall survival in rheumatoid arthritis. Arthritis Rheum 2013; 65: 334-342.

24. Arena U, Stasi C, Mannoni A, et al. Liver stiffness correlates with methotrexate cumulative dose in patients with rheumatoid arthritis. Dig Liver Dis 2012; 44: 149-153.

25. Rouhi A, Hazlewood G, Shaheen AA, et al. Prevalence and risk factors for liver fibrosis detected by transient elastography or shear wave elastography in inflammatory arthritis: a systematic review. Clin Exp Rheumatol 2017; 35: 1029-1036.

26. Fitzpatrick R, Scott DG, Keary I. Cost-minimisation analysis of subcutaneous methotrexate versus biologic therapy for the treatment of patients with rheumatoid arthritis who have had an insufficient response or intolerance to oral methotrexate. Clin Rheumatol 2013; 32: 1605-1612.

27. Rutkowska-Sak L, Rell-Bakalarska M, Lisowska B. Rola doustnej bądź podskórnej drogi podania małych dawek metotreksatu w redukcji objawów niepożądanych ze strony układu pokarmowego. Reumatologia 2009; 47: 207-211.

28. Li D, Yang Z, Kang P, Xie X. Subcutaneous administration of methotrexate at high doses makes a better performance in the treatment of rheumatoid arthritis compared with oral administration of methotrexate: A systematic review and metaanalysis. Semin Arthritis Rheum 2016; 45: 656-662.

29. Bianchi G, Caporali R, Todoerti M, Mattana P. Methotrexate and rheumatoid arthritis: current evidence regarding subcutaneous versus oral routes of administration. Adv Ther 2016; 33: 369-378.

30. Wluka A, Buchbinder R, Mylvaganam A, et al. Long term methotrexate use in rheumatoid arthritis: 12 year follow up of 460 patients treated in community practice. J Rheumatol 2000; 27 : 1864-1871. 